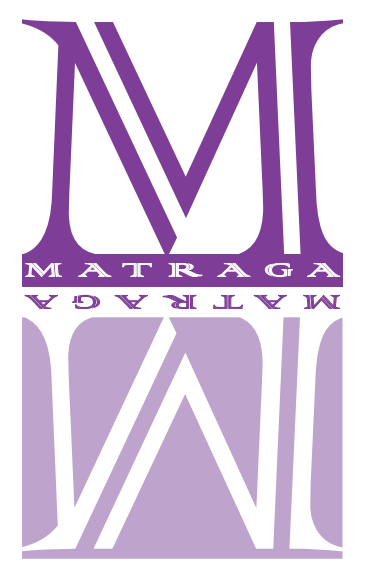

\title{
Da revista ao livro: Brandão entre o mar e 0 amor (1941), ficção coletiva e realismo na Geração de 1930
}

\author{
Haroldo Ceravolo Sereza \\ PPGLIT-Universidade Federal de São Carlos, Brasil \\ http://orcid.org/0000-0002-5738-8398
}

\begin{abstract}
RESUMO
A publicação no início dos anos 1940, na revista Diretrizes, de Brandão entre o mar e o amor, assinado por Jorge Amado, José Lins do Rego, Graciliano Ramos, Aníbal Machado e Rachel de Queiroz, teve de obedecer aos limites impostos pela censura do Estado Novo, que procurava subordinar as publicações às conveniências das alianças externas do país num tempo de guerra. Misto de projeto de ficção e de engajamento dos leitores numa campanha jornalística e publicitária, a obra expõe também projetos literários realistas concorrentes dentro da Geração de 1930. As inconsistências da trama e os contrastes formais permitem observar como escritores que são aproximados pela tradição e pelo cânone expressam culturas, posições políticas e interesses nem sempre conciliáveis. Por outro lado, a falta de unidade na obra expõe também características da literatura pensada para ser lida, primeiramente, em periódicos, e não em livros.
\end{abstract}

PALAVRAS-CHAVE: Realismo; Jornalismo; Romance coletivo; História literária; Geração de 1930.

From magazine to book: Brandão entre o mar e o amor (1941), collaborative fiction and realism in the 1930 generation

\section{ABSTRACT}

In the begging of 1940's, Brandão entre o mar e o amor (Brandão between sea and love) was published in the magazine Diretrizes. It obeyed limits imposed by the censorship of Brazilian government at the time, which sought to subordinate publications to the conveniences of the country's external alliances in the first years of the Second World War. The novel was a combination of a fictional and journalistic project, allied to an advertising initiative. It was supposed to engage readers and seduce them by the participation of well-known realistic Brazilian writers such as Jorge Amado, José Lins do Rego, Graciliano Ramos, Aníbal Machado e Rachel de Queiroz. Despite being signed by notorious writers of the 1930 Generation, the result was a lot of inconsistencies in the plot, and several formal contrasts among the chapters, showing incompatible political and aesthetics positions within the group. On the other hand, the lack of unity in this work also exposes the marks of a literature thought to be read first in periodicals, not in books.

KEYWORDS: Realism; Journalism; Collaborative fiction; History of literature; The 1930 Generation. 


\section{As questões que nos movem}

Brandão entre o mar e o amor, novela ${ }^{1}$ escrita por Jorge Amado, José Lins do Rego, Graciliano Ramos, Aníbal Machado e Rachel de Queiroz, reúne nomes canônicos do romance de $1930^{2}$ e participantes de um projeto de literatura engajada em questões sociais do período ${ }^{3}$. Ao colocá-los lado a lado, a obra ficcional acaba por explicitar importantes distâncias estilísticas e de visão de mundo entre eles, que tinham em comum um projeto de matriz realista (que retoma a herança realista e naturalista do século XIX numa nova chave), mas que, também, adotam modos distintos de abordar a realidade e de se posicionar frente a ela.

Por outro lado, na História Literária, é frequente o apagamento de processos jornalísticos e mercadológicos que dão origem a obras ficcionais. Tal apagamento costuma ser tão mais intenso quanto mais canônica a obra, como se fosse necessário apagar a "origem mundana" para que a literatura adquira a aura de obra de arte. Este artigo procura responder a esses dois problemas: identificar, num mesmo projeto, a heterogeneidade de um grupo normalmente associado a um rótulo comum; e registrar o processo de construção de um livro coletivo. Ao indicar os elementos condicionantes da produção, buscamos também apontar caminhos encontrados pelos autores para representar, através da literatura, conflitos decorrentes de processos históricos em andamento, sobretudo a Segunda Guerra Mundial, em sua interação com a realidade brasileira cotidiana - em outras palavras, como eles buscaram criar o "efeito do real" (BARTHES, 1971).

\section{0 projeto jornalístico}

Nas páginas 5 (Figura 1), 16 e 23 da Diretrizes do dia 31 de julho de 1941, foi apresentado ao público da revista o projeto de publicação de uma obra escrita por cinco grandes escritores. Tratava-se de Brandão entre o mar e o amor, "a primeira novela coletiva da literatura moderna no Brasil” (DIRETRIZES, 1941, n. 58, p. 5).

Os autores das cinco partes foram nominados ${ }^{4}$, , mas a assinatura de cada um dos trechos seria omitida: numa espécie de concurso, caberia ao leitor adivinhar quem era o responsável pela escrita de cada trecho e enviar seu palpite à redação da revista, passando, em caso de acerto, a concorrer a livros da editora Martins (Figura 2). "Quando anunciamos há alguns meses que cinco dos maiores escritores da moderna novelística brasileira tinham concordado em escrever, especialmente para esta revista, uma novela inédita, não poucos foram os que se mostraram incrédulos na realização deste empreendimento" (DIRETRIZES, 1941, p. 5), afirmou a revista.

\footnotetext{
${ }^{1}$ Alguns dos críticos e jornalistas que produziram a pequena fortuna crítica de Brandão entre o mar e o amor se referem ao livro como romance. Preferimos, aqui, adotar a nomenclatura dada por seus criadores - novela.

2 Mineiro de Sabará, Aníbal Machado destoa em alguns aspectos do grupo, pois é mais conhecido como contista, sobretudo pelos textos "A morte da porta-estandarte", "Viagem aos seios de Duília", "0 iniciado do vento" e "Tati, a garota", todos também adaptados para o cinema. Seu romance, João Ternura, lírico e vulgar, iniciado em 1926, só foi lançado em 1965, após sua morte (ENCICLOPÉDIA, 2021, verbete Aníbal Machado).

${ }^{3}$ Em Uma história da Geração de 30, há uma interessante discussão sobre a permanência da literatura empenhada em questões sociais na Geração de 1930, desde a introdução, e sobre o apagamento dos "autores ditos intimistas" (BUEN0, 2006, p. 17).

${ }^{4}$ Marcos Vinícius Teixeira (2019, p. 156) observa que os autores têm origem em cinco estados diferentes (Bahia, Pernambuco, Alagoas, Minas Gerais e Ceará, na ordem dos capítulos), embora todos vivessem já no Rio.
} 
FIGURA 1. Página apresentando a novela coletiva com o resumo do projeto, os perfis de cada autor, o desafio ao leitor (pé da página, à esquerda) e os prêmios em disputa (à direita). Diretrizes, n. 58, 31/07/1941, p. 5.

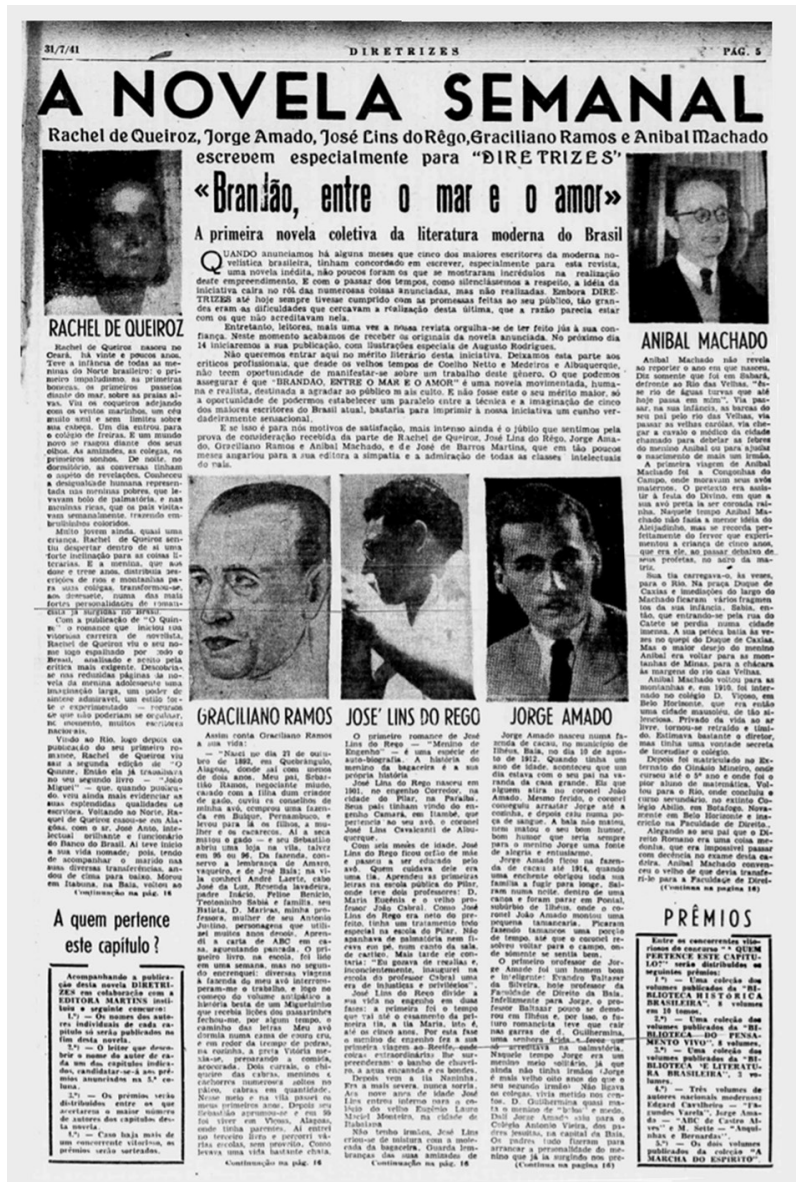

FIGURA 2. "De quem é este capítulo?": formulário para os leitores interagirem com Diretrizes, publicado junto dos textos da novela.

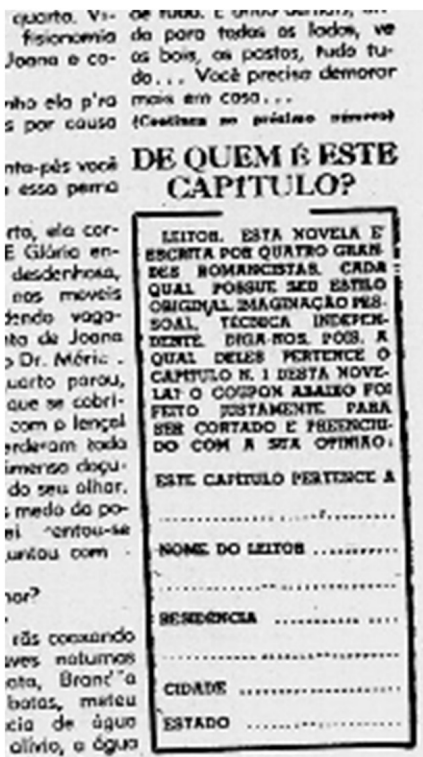


Ao fim da publicação periódica, os autores de cada trecho seriam revelados, e a obra ganharia, já em 1942, a primeira edição em livro, pela própria Martins, que o reimprimiu pelo menos uma vez com uma nova capa. Brandão entre o mar e o amor seria relançado em 1973 pela mesma editora e, em 1981 e 2000, pela Record. A última dessas edições foi patrocinada por uma bandeira de cartão de crédito e enviada como brinde a clientes de um banco; seu miolo era uma simples reprodução da edição de 1981 (Figura 3). É interessante notar que a primeira e a terceira capas induzem a uma leitura de "entre o mar e o amor" como subtítulo, como aliás fez Diretrizes na edição do primeiro capítulo (Figura 1), enquanto as demais sugerem uma leitura direta, "Brandão entre o mar e o amor", com o nome da personagem principal perdendo destaque, o que ocorreu também na revista ao longo da publicação original. Adotamos neste texto a formulação Brandão entre o mar e o amor sabendo que nenhuma das duas se consolidou.

FIGURA 3. colagem das capas do romance da primeira à mais recente edição, feita a partir de imagens de arquivo pessoal e do Google Images.
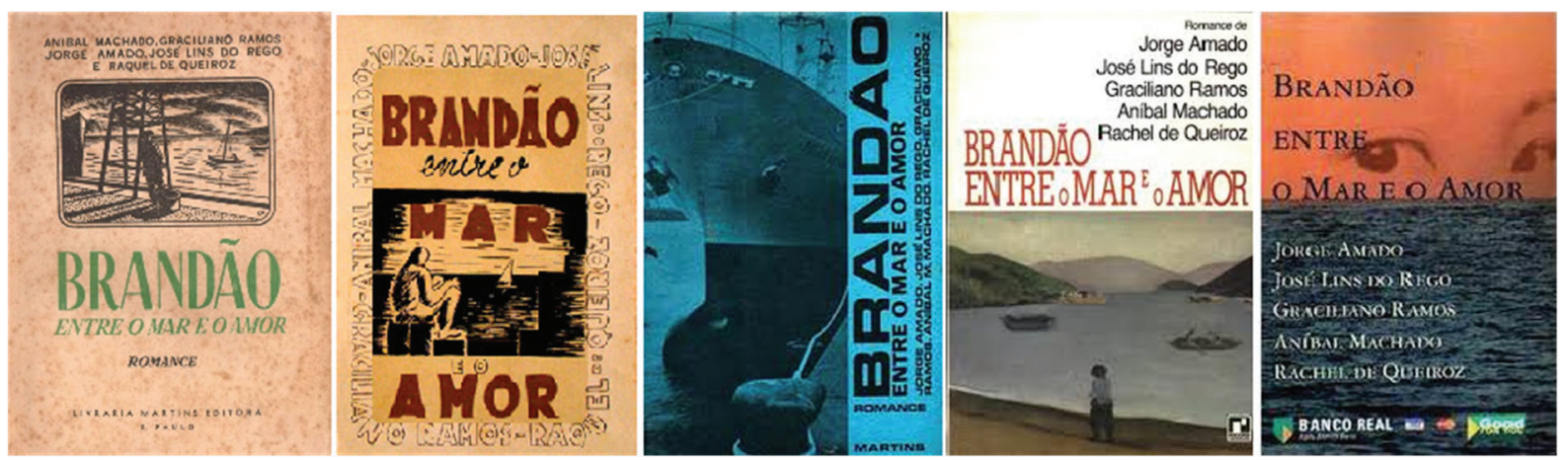

A relativamente fértil vida editorial do livro se explica, em boa medida, pela reunião de autores que já eram considerados importantes em 1941 e passaram a figurar no cânone literário brasileiro do século XX. A presença de Amado, Lins do Rego, Graciliano e Rachel seria suficiente, hoje, para garantir algum interesse comercial e literário pelo livro; por outro lado, este fato talvez seja um dificultador na atualidade por conta da complexa negociação dos direitos autorais com os herdeiros dos ficcionistas, todos já mortos.

A possibilidade de engajar tais escritores num trabalho coletivo, nos anos 1940, deve-se à trajetória construída de Diretrizes. O esforço em reunir esse naipe de autores e o concurso de adivinhação como instrumento de propaganda e de criação de um leitorado fiel são reveladores do projeto da revista. O periódico era dirigido essencialmente pelo jovem Samuel Wainer, que buscava imprimir um caráter mais popular, com formato de jornal, à revista. Esse foi, assim, seu primeiro grande projeto jornalístico, laboratório para experiências que Wainer, nos anos 1950, conduziria, após sua aproximação com Getúlio Vargas, para o diário Última Hora.

A revista Diretrizes original surgira em 1938, sem periodicidade fixa, sob a direção de Azevedo Amaral, secretariado por Wainer. Tinha um aspecto mais simples e pauta essencialmente política, num sentido estrito. Apesar da diagramação interna "careta”, a capa do primeiro número já demonstrava certa ousadia. Assinada pelo artista gráfico Tomás Santa Rosa, trazia uma co- 
lagem que incluía um grande edifício, um olho solto no céu, um desenho de inspiração egípcia, um homem segurando uma câmera e um rosto assustado.

Azevedo Amaral era formado em medicina, embora não a exercesse. Ligado ao Partido Republicano Paulista ao longo da Primeira República, apoiou Júlio Prestes na eleição de 1930, mas acabou por converter-se ao projeto do Estado Novo, do qual tornou-se um ideólogo. Poucos meses antes de fundar Diretrizes, publicou o livro Estado autoritário e a realidade nacional (AMARAL, 1938). Deficiente visual, contou com o apoio da Light and Power Company para o lançamento da revista. Segundo relata Danilo Wenseslau Ferrari,

Amaral conseguiu verba de dois contos de réis junto à estrangeira Light and Power para o lançamento da nova revista. O primeiro número veio ao público em abril de 1938. A média de sessenta e quatro páginas era impressa em papel jornal e o couché era reservado às capas em formato $18,5 \times 27 \mathrm{~cm}$ que exibiam fotografias na maioria das vezes. O subtítulo de Diretrizes era Política, Economia, Cultura e a escritura do editorial esteve a cargo de Amaral durante os sete meses em que foi o responsável pela revista (FERRARI, 2008, p. 3).

As posições políticas de Amaral entraram em choque com a de alguns colaboradores (FERNANDES, 2014, p. 50). Já nessa fase, escreveram na revista simpatizantes da esquerda, como Álvaro Moreyra, Carlos Lacerda, Nelson Werneck Sodré e Graciliano Ramos. Também foram publicados textos de escritores estrangeiros progressistas, como Ernest Hemingway e Aldous Huxley. "A incompatibilidade de visão política entre os colaboradores de Diretrizes e Azevedo Amaral foi um dos motivos para que este deixasse a liderança do periódico", escreve Ferrari. "No entanto, o fator determinante na querela seria o desentendimento com Samuel Wainer, que teria aproveitado da cegueira do patrão e registrado a revista apenas em seu nome" (FERRARI, 2008, p. 4).

A tensa saída de Amaral, que fundaria a Nova Diretrizes, carregando consigo a subvenção da Light, abriu espaço para que Wainer pusesse em andamento um projeto mais arejado politicamente e com vocação mais popular. Diretrizes deixou de defender o Estado autoritário e passou a se posicionar em editoriais contra os Estados de inspiração fascista e nazista. Um dos seus diretores, Octávio Malta, era integrante do Partido Comunista (PCB) e buscava influenciar a revista, que tinha, também, de lidar com as pressões do aparelho de Estado getulista, não raro fazendo concessões significativas. Em várias ocasiões, "os editores inseriram material de propaganda que o DIP [Departamento de Imprensa e Propaganda] impunha à imprensa na intenção de forjar uma imagem positiva do Brasil e do presidente" (FERRARI, 2008, p. 4).

A própria edição de Brandão entre o mar e o amor em folhetim e do concurso imaginado pela redação de Wainer foi significativamente prejudicada: da publicação do primeiro capítulo até o fim do projeto, em 26 de fevereiro de 1942, o nome de Jorge Amado ficou oculto do público, como se os cinco capítulos de Brandão entre o mar e o amor fossem obra apenas de seus quatro colegas. Esse período coincide, aproximadamente, com o exílio de Jorge Amado na Argentina e a proibição de publicidade de seu livro $A B C$ de Castro Alves. O fim da proscrição ocorreria só no anúncio da publicação em livro da novela, em 30 de julho de 1942, um mês antes de o Brasil, oficialmente, declarar guerra aos países do Eixo, colocando-se com Reino Unido, Estados Uni- 
dos e União Soviética, entre os aliados. A conjuntura política abranda a censura, e Jorge Amado volta a figurar como um dos autores (DIRETRIZES, 1942, n. 109, p. 21).

Do ponto de vista da viabilidade econômica, no entanto, foi a entrada de Maurício Goulart na sociedade, em dezembro de 1940, que permitiu o impulso formal de Diretrizes, abrindo espaço para uma nova leva de escritores colaboradores, como Manuel Bandeira, Oswald de Andrade e Cecília Meireles, entre outros, além dos autores de Brandão entre o mar e o amor. Alguns capítulos de $A B C$ de Castro Alves também foram publicados primeiramente na revista. De acordo com Wainer, Goulart, que estivera ligado à Aliança Nacional Libertadora, em 1935, tendo sido detido por participar de um comício, foi procurado por ele e por Rubem Braga. "Ele logo se entusiasmou com a ideia e aceitou investir cem contos de réis - uma fortuna" (WAINER, s/d, p. 58), passando a figurar como diretor, até dezembro de 1942. Além disso, conseguiu novos anunciantes para Diretrizes, que teria alcançado uma tiragem de vinte mil exemplares.

A partir desse rearranjo, uma série de mudanças tornou a revista mais “jornalística”. A capa passou a contar com imagens ocupando todo o espaço da página, e as chamadas de conteúdo cederam espaço às curtas manchetes: "O subtítulo Política, Economia, Cultura suprimiu-se. O formato aumentou para $48 \times 28 \mathrm{~cm}$, semelhante a um tabloide. Além das folhas impressas em papel jornal, a revista apresentava-se ao público com primeira página”. No número 37, em 6 de março de 1941, a revista anunciava:

Ao completar o seu terceiro aniversário, Diretrizes aparece num formato inédito no Brasil. Aparece firmando-se como semanário moderno, maior, mais variado, mais atual, mais artisticamente cuidado, mais popular. E aparece assim porque o povo a favoreceu com sua grande e generosa simpatia e o seu apoio material (DIRETRIZES, 1941, n. 37, p. 2).

É a liderança de Wainer e a presença de tantos intelectuais e escritores progressistas que permitirão a Diretrizes ser saudada, por Nelson Werneck Sodré, na História da imprensa no Brasil, como uma exceção em meio à tendência evasiva do jornalismo da época:

Com esforços curiosos, muita malícia e alguma ousadia, passando assuntos entre as estreitas malhas do vastíssimo rol de assuntos proibidos, essa revista teve, realmente, papel de relevo na época, que foi ainda maior à medida que, desde 1942 - o ataque japonês a Pearl Harbour ocorreu a 6 de dezembro de 1941 - os Estados Unidos juntaram-se aos aliados. A participação da União Soviética na guerra, forçando a suspensão da propaganda anticomunista no ocidente, permitiu o combate ao nazifascismo e o Estado Novo começou a ser esvaziado de seu conteúdo originário e a debilitar-se (SODRÉ, 1999, p. 386).

A publicação de Brandão entre o mar e o amor, anunciada no número 58, inicia-se no número 62, em 28 de agosto de 1941, mantendo a regularidade semanal da revista ${ }^{5}$. A linha liberal oposicionista teria como resultado diversas apreensões com a polícia e com o Departamento de Imprensa e Propaganda (DIP). A revista seria fechada em 1944 devido à pressão governamental, reabriria em 1945 e encerraria as atividades no final dos anos 1940.

\footnotetext{
${ }_{5} 0$ primeiro capítulo, de Jorge Amado, seria publicado em partes, do número 62 ao 67, este último em 2 de outubro de 1941.
} 
A trajetória de Diretrizes é absolutamente relevante para entender a construção da novela coletiva. Seu perfil condiciona a produção do texto, que é inicialmente pensado na lógica do jornalismo em revista, e não na do livro, o que impõe características à trama. A combinação de elementos caros à lógica jornalística com as pressões que a imprensa e a intelectualidade enfrentavam diante do cenário de uma Guerra Mundial atuam, inclusive, sobre o enredo, que expressa, às vezes de modo explícito (especialmente nos trechos de Aníbal Machado e Rachel de Queiroz), outras vezes de modo menos evidente, as tensões do ambiente político da época. A escrita a dez mãos potencializa a expressão dessas tensões, pois as narrativas ganham formas e lógicas heterogêneas, ainda que realizadas por autores tradicionalmente aproximados pelas histórias da literatura.

\section{Semelhanças e diferenças literárias}

Como obra coletiva, da apreensão do literário, Brandão entre o mar e o amor tem um grande mérito: explicita, de maneira muito objetiva, esses diferentes estilos e nuances ideológicas. A leitura completa da novela sugere não ter havido um planejamento prévio efetivo por parte do grupo. Pelo contrário, nos relatos de Graciliano Ramos e Rachel de Queiroz, os escritores relatam uma memória de ampla liberdade para dar continuidade à trama até então escrita, sem um compromisso de consultas entre eles. Assim, o entrecho inicial de Jorge Amado constitui uma peça fundamental na leitura da obra. É a partir do que ele propõe que os demais escritores seguirão adiante, submetendo-se ou não à linha inicial, indicando assim seus pontos de aproximação e distanciamento estético e político.

A proposta feita por Amado, aparentemente simples e açucarada, de um triângulo amoroso com o veredicto de morte de um de seus integrantes (mas com uma sugestão filosófica significativa), segue caminhos inusitados. Lins do Rego e Graciliano realizam mergulhos sociológicos e, especialmente no segundo caso, psicológicos; Rachel exibe, ao dar solução para os conflitos, um controle da técnica narrativa bastante acentuado, ainda que também mostre uma forte tendência para soluções conciliadoras; Aníbal Machado, o contista, é responsável pelo maior dos capítulos e revela-se o mais interessado em explicitar as relações entre a realidade imediata da guerra e a narrativa.

Jorge Amado inicia a novela apresentando em "Mais que branca, mais que pálida" (AMADO, 2000, p. 7) - título que só apareceria na edição em livro (cuja capa levava, também, a assinatura de Santa Rosa) - os personagens Lúcia, seu marido Pedro Brandão e Mário, colega de faculdade de Brandão. Mário está na fazenda de Brandão, sendo tratado de um ferimento por Lúcia. "Que cor ela tinha, mais que pálida, mais que branca, uma cor diferente, lembrando mistura de raças, algum avô mandarim" (AMADO, 2000, p. 9-10), informa o narrador, revelando o encanto de Mário por Lúcia, para depois descrever as sensações que ela evocava por essa origem difusa: "Bastava baixar a boca e teria nos lábios o gosto daquele cangote, o perfume que se evolava dele, o mistério da cor daquela carne" (AMADO, 2000, p. 10). Ao sugerir a ascendência chinesa, Amado abre espaço para um entrecho internacionalizado. Essa escolha resulta, também, numa das maiores confusões e numa das questões mais mal resolvidas da trama: qual seria, afinal, a 
origem de Lúcia? Chinesa (avô mandarim), japonesa, emigrante de Samoa ou de alguma outra região do sudeste asiático não identificada?

Cada autor apontará numa direção, nem sempre se apoiando numa dúvida, como fizera Amado e como faz Graciliano (“a pele de cor indecisa”, RAMOS, 2000, p. 65), sugerindo posicionamentos em relação ao conflito em andamento: se Lúcia é chinesa, estamos diante da representação alegórica de uma oprimida vivendo num país distante, indecifrável, fragilizado; quando Lúcia é apresentada como japonesa, como faz Aníbal Machado, torna-se uma opressora, quase inimiga - "Depois da conversa em japonês, Lúcia parecia-lhe menos familiar ainda, mais distante do mundo brasileiro, de Pau-d'Arco, da vida e de seu filho" (MACHADO, 2000, p. 122) -, enquanto outras opções são menos emblemáticas e apelam mais a uma imagem de exotismo e erotismo. Raquel de Queiroz, por sua vez, dará a esse conflito entre os autores uma solução prosaica, "corrigindo" na marra as contradições anteriores: ela é brasileira filha de pai japonês, de Marília, interior de São Paulo (QUEIROZ, 2000, p. 138-139), explica a personagem Lúcia no quinto e último capítulo. Como tantos outros filhos de imigrantes, estava entre dois mundos, mas distante do conflito internacional.

Jorge Amado prioriza, como estrutura central de seu capítulo, o triângulo amoroso, anunciado quando Mário, depois de admirar-se com a beleza de Lúcia, que lhe faz um curativo, pergunta-lhe: “Tu és feliz?”. Essa questão causa um grande embaraço a ambos:

A transformação do rosto dela o amedrontou. Parecia que o odiava por ter-lhe perguntado aquilo, a folha, machucada por sua mão que se fechara, estalou no quebrar das fibras secas. E aquela expressão de ódio terrível, que dava ao seu rosto um ar de máscara de tragédia, e as mãos cerradas como se quisesse lhe bater no rosto (AMADO, 2000, p. 13).

A opção de Amado guarda relação com um de seus primeiros romances, O país do Carnaval (1931), em que a busca de uma felicidade impossível conduz a trama. Também, de maneira desta vez mais suave, por meio de Lúcia, a questão da nacionalidade é posta em perspectiva, enquanto em O país do Carnaval o problema surge por meio da personagem principal, Paulo Rigger, que vivera sete anos em Paris e chega a declarar, numa construção brutalmente autoritária, que só se sentiu brasileiro duas vezes: "Uma no carnaval, quando sambei na rua Outra, quando surrei Julie, depois que ela me traiu" (AMADO, 2010, p. 68).

Esposo de Lúcia, Brandão é um aventureiro, que fora artista de circo e se tornara marinheiro - e via no mar, ou seja, no desconhecido, sua vocação, o local em que se sentia verdadeiramente feliz: "Donde se vê que eu te amo mais que mesmo ao mar, pois não tive dúvidas em deixá-lo para viver contigo... E não tive medo que a lua de mel acabasse..." (AMADO, 2000, p. 40), diz Brandão a Lúcia. No jogo de oposições construído por Amado, Brandão fica entre a aventura e o cotidiano, o mar e a fazenda, o tumulto das tormentas e a calmaria expressa por seu amor e pela postura de Lúcia. Os mistérios em torno de Lúcia, com seus passos de ave ("seu passo miúdo de filha de outras raças", AMADO, 2000, p. 25), de sua origem e de sua cor ("aquela cor sem palavras que a definissem", AMADO, 2000, p. 23), representam a força que mantém Brandão ligado à terra, apesar do impulso de lançar-se ao mundo. 
A perspectiva de explorar cor exótica e raça da personagem, no entanto, se perde já na segunda parte, o que é revelador de como esses temas parecem ser muito mais caros a Amado do que a seus contemporâneos. Lins do Rego não apenas dá pouca atenção à cor e à origem de Lúcia como abandona a trama complexa do início, cheia de personagens, para fixar-se sobretudo em Glória ${ }^{6}$. Ela, sob a pena de Lins do Rego, se apaixonará por Brandão, estabelecendo, assim, um romance cruzado entre quatro personagens de personalidades bastante distintas - que, simplificadamente, poderíamos chamar de o aventureiro Brandão, a misteriosa Lúcia, o fracassado Mário, a mimada Glória. Lins do Rego mantém, no entanto, uma sugestão relevante para a trama feita por Jorge Amado: a busca de uma questão que oriente o capítulo. Se Mário pergunta a Lúcia e, de um certo modo, a si próprio, se são felizes, Lins do Rego fará Glória, uma vaidosa órfã de mãe crescida sob os cuidados extremos do pai, duvidar de si mesma: "Será que não podia amar?" (REGO, 2000, p. 50). Lins também parece interessar-se pelas questões raciais sugeridas por Jorge Amado, mas lhes dá um tom mais local, aprofundando a relação entre Glória e o casal negro Joana e Vicente. Acrescenta também a temática religiosa, com a inclusão de Pai Leandro como figura importante da novela. Este será procurado por Glória, que busca apoio para o desejo de conquistar Brandão.

Graciliano, de certo modo, aproxima-se de Lins do Rego ao dar sequência à novela, com passagens memoráveis, fixando-se em Mário, então doente, aparentemente de tuberculose, delirante e febril: o suor abundante, o desejo de escrever, a dúvida sobre deixar ou não a fazenda, a perda de suas memórias. Sua paralisia durante o capítulo todo (ele nunca sai do quarto) se opõe às viagens pelo mundo de Brandão. A doença o amarra à cama, ao sofrimento, por uma força negativa quase que intransponível. Como Luís da Conceição, de Angústia (1936), Mário é marcado pela abulia, que supera parcialmente ao escrever seu diário, cujos trechos marcam o incômodo com a situação e com a inveja e, ao mesmo tempo, a aversão da vida do amigo: "Brandão é um vagabundo, sempre teve aquela mania de correr terra. Será desejo de observar, instruir-se, ou será impossibilidade de ficar quieto?” (RAMOS, 2000, p. 80). Mesmo Brandão, no entrecho de Graciliano, ganha ares mais reflexivos, ao explicitar, num diálogo, como avalia a própria doença e a contraditória condição de homem forte destinado a morrer: "É o diabo, menino. Você vê este corpão duro, com muito osso por dentro e muito calo por fora, e nem adivinha. Deu cupim nele, está tudo bichado. Mergulho qualquer dia” (RAMOS, 2000, p. 74). Cabe registrar, ainda, que Graciliano recorrerá à explicitação de uma pergunta que oriente seu capítulo. Depois de sua personagem central, Mário, recusar o tema da novela ("Amor? Essa palavra acanalhou-se"), pois "não se conforma com aquela imprecisão", colocará essa questão: "Que é que está sentindo?” (RAMOS, 2000, p. 70), uma pergunta que vale tanto para a parte física - a doença - quanto emotiva - a paixão por Lúcia -, ambas sem uma resposta definitiva no capítulo.

Caberá a Aníbal Machado retomar uma narrativa mais ampla, com o trecho "O mar triunfante", em que Brandão abandona o campo - e por conseguinte o amor - em busca de novas aventuras na Marinha Mercante, em plena Segunda Guerra. Nesse momento, o conflito invade,

\footnotetext{
${ }^{6}$ Além dos três principais personagens, são apresentados no primeiro capítulo o pai de Brandão, juiz de direito, sua esposa, d. Elizabeth, Glória, a mulher de Mário, a costureira Joana e seu marido Vicente.
} 
sem rodeios, a obra. Com seu trecho, Machado busca dar um sentido político explícito a tudo o que até então foi narrado, e esse movimento se reforça, sobretudo, pela reconciliação de Brandão com a mãe. Aníbal até ensaia uma pergunta genérica - "Que é viver, minha filha?" -, feita "timidamente" pelo pai de Glória (MACHADO, 2000, p. 121). A pergunta, no entanto, é bem menos relevante do que as feitas nos capítulos anteriores, adotando este autor um projeto mais pragmático de solucionar questões do enredo.

Depois de caracterizar Lúcia como japonesa, Aníbal Machado leva D. Elisabeth a entender o gosto pela aventura e o heroísmo do filho como qualidades. Afinal, ele cruza os mares na condição de um marinheiro engajado no esforço de guerra das forças aliadas. Embora não seja explícito em sua narrativa, quando Brandão abandona a fazenda, também abandona Lúcia, o que, por extensão, simboliza um abandono do Japão e do Eixo. O escritor conclui, assim, o quarto capítulo:

Exaltada por uma embriaguez que nunca experimentara na vida, gritou ainda mais alto, enquanto o vento lhe agitava a cabeleira branca:

- Ele teve razão! Ele fez muito bem! Ele sabe o que faz!... Fica, meu filho, fica no mar quanto tempo queiras... Agora te compreendo!... Só agora!... (MACHADO, 2000, p. 130)

Se Aníbal Machado procura dar destino a diversas questões mal resolvidas dos capítulos anteriores, é Rachel de Queiroz quem vai trabalhar duro para encerrar a obra com alguma coerência. Lúcia, assim, tem finalmente a oportunidade de explicar a Brandão que é, na verdade, japonesa de uma família de Marília, interior de São Paulo, e que nunca esteve em Bangcoc, como havia sido dito ao marido. Brandão e Lúcia terão uma longa conversa na capital da Bahia, em que Rachel de Queiroz pode equacionar diversas ambiguidades.

A nos fiarmos em relato feito em 1981 por Angela Leite de Souza em O Globo, os escritores da obra coletiva não tinham conhecimento do que os demais escreviam. A descrição parece improvável, uma vez que, apesar dos desencontros, o encadeamento temporal interno da obra não é rompido, e parece bastante difícil que isso fosse possível sem que houvesse algum tipo de informação bastante precisa. Assim, parece-nos mais razoável supor que cada autor tenha escrito seu capítulo depois de ler o feito por seu antecessor, sem, no entanto, sugerir modificações retroativas. Rachel de Queiroz, assim, foi responsável por dar um ponto final ao trabalho. Ao conceder entrevista sobre o processo que levou à construção de Brandão entre o mar e o amor, explicou como buscou um "método" para dar conta dos desarranjos da obra: "Para resolver tudo da melhor maneira, comecei a matar todo mundo, e a história se acabou por falta de personagens" (QUEIROZ in MENEZES, 1981, p. 34).

\section{Considerações finais}

Em um artigo escrito sobre Brandão entre o mar e o amor, intitulado "Masculinity and Disease: the Male Body in the co-authored novel Brandão entre o mar e o amor" (VILLARES, 2013), a crítica Lucia Villares observa argutamente que, mesmo sendo uma obra coletiva, fazia parte 
do projeto manter a identidade de cada um dos autores: a ideia não era fundir os estilos - pelo contrário, o concurso estabelecido por Diretrizes exigia explicitude das diferentes estratégias narrativas, uma vez que o público tinha a "missão" de detectar quem escreveu cada parte. Ou seja, a forma de publicação em folhetim da revista dirigida por Samuel Wainer e o concurso de apelo publicitário que organizou essa publicação favoreceram que os autores deixassem marcas pessoais de sua escrita na obra. Portanto, ficaram preservadas ou mesmo reforçadas tanto as diferenças de estilo quanto as relações entre os trechos da novela e as condições políticas do momento.

A partir dessa sugestão, observamos que Aníbal Machado é o autor que mais provoca aproximações entre o conflito mundial e a obra, enquanto essas relações ficam menos explícitas em Graciliano Ramos e Lins do Rego. No trecho de Jorge Amado, a situação mundial parece sugerir a construção das personagens Brandão e Lúcia, embora a relação com a guerra não ganhe explicitude. Rachel de Queiroz tratará da situação procurando reduzir o peso do cenário internacional na obra, fazendo Brandão ter de desistir, por conta da doença cardíaca, da vida de marinheiro, e abrandando a hereditariedade japonesa de Lúcia. Ou seja, ela reconhece a aproximação com o cenário internacional, mas busca, como solução de compromisso, anular muitos dos sentidos dados anteriormente. Sua capacidade técnica encontra soluções razoavelmente verossímeis, mas, ao mesmo tempo, desidrata posicionamentos políticos, referências à guerra e a sofisticadas construções psicológicas.

Villares considera "interessante notar que um grupo de escritores em que muitos tinham ideias comunistas [além de Jorge Amado, Graciliano Ramos e Rachel de Queiroz foram, em diferentes momentos da vida, filiados ao partido] não se tenha optado por um real e profundo processo de criação coletiva" (2013, p. 16, tradução do autor), escreve ela. Graciliano Ramos, em pelo menos uma ocasião, fez uma menção a Brandão bastante negativa num discurso a companheiros do PCB:

\begin{abstract}
De que modo se realiza a produção? Evidentemente é razoável que os eruditos se associem: não conceberíamos a Enciclopédia Britânica redigida por uma pessoa. A criação, porém, é rigorosamente individual: absurdo imaginarmos quadros e poemas compostos por diversas criaturas; tentativas malograram-se; aqui há tempo alguns literatos fabricaram, com infelicidade notável, uma espécie de romance - um desastre (citado por GIMENEZ, 2009, p. 248). ${ }^{7}$
\end{abstract}

O ensaio de Villares trata da novela como um todo, mas tem como questão central a diferença dos corpos de Brandão e Mário. O corpo de Brandão é apresentado sobretudo por Jorge Amado (e complementado por Aníbal Machado e Rachel de Queiroz), enquanto Mário é descrito sobretudo por Graciliano. Villares identifica no corpo de Brandão um engajamento em três

\footnotetext{
${ }^{7}$ Arquivo Graciliano Ramos - IEB/USP; série: Manuscritos; Pasta: discursos. De certo modo, o incômodo de Graciliano repete o de uma outra obra coletiva da língua portuguesa, 0 Mistério da Estrada de Sintra, de Eça de Queirós e Ramalho Ortigão. Em 1884, quatorze anos após a edição em folhetim, Queiroz e Ortigão "justificam" a publicação em livro do trabalho: "Como permitimos pois que se republique um livro que, sendo todo de imaginação, cismado e não observado, desmente toda a campanha que temos feito pela arte de análise e de certeza objectiva? Consentimo-lo porque entendemos que nenhum trabalhador deve parecer envergonhar-se do seu trabalho" (QUEIR0Z, 1958, v. 3, p. 1272).
} 
diferentes frentes: o processo de colonização do Brasil, a expansão do comunismo e a Segunda Guerra. Sua masculinidade é típica de um herói do realismo socialista ${ }^{8}$ forte, positiva, capaz de espalhar a revolução e a mudança social pelo mundo, tornando irrelevantes as diferenças nacionais. Apesar de doente, e de morrer em decorrência dessa doença cardíaca, sugerida por Jorge Amado, nas mãos de Rachel de Queiroz, nada o impede de realizar proezas: seu corpo é absolutamente funcional. Segundo Villares, esse corpo não se presta exatamente à observação: está lá para ser eficiente. Desse modo, expressa também uma sexualidade mais tradicional, que se contrapõe à de Mário.

Como ocorre com outras personagens masculinas de Graciliano (em Angústia e Infância [1945], por exemplo), o corpo de Mário é extremamente visível, presente, explícito. Sua doença física e mal-estar psicológico são descritos de modo detalhado. Antonio Candido, em Ficção e confissão, mostra que, para o prisioneiro de Memórias do cárcere, "a literatura é o seu protesto, o modo de representar o mundo das normas constritoras" (CANDIDO, 1999, p. 68): o diário de Mário cumpre, em Brandão entre o mar e o amor, um papel semelhante.

Contabilizamos, assim, algumas diferenças presentes ao longo dessa novela coletiva: as diferentes perguntas que orientam os capítulos; a assimetria entre os corpos de Mário e Brandão e também os diferentes projetos de vida - Mário quer registrar os seus sentimentos, Brandão parece escrever sua vida num mar de aventuras, o que o primeiro considera uma vida sem profundidade: "Se Brandão tivesse curiosidade, teria permanecido num lugar, numa rua, numa casa, estudando com paciência as pessoas e as coisas" (RAMOS, 2000, p. 80); a preferência pelo mergulho em personagens individuais (Graciliano e Lins do Rego) em contraposição à opção por uma trama dispersa (Jorge Amado, Aníbal Machado e Rachel de Queiroz); como caracterizar o mistério oriental de Lúcia (chinesa ou japonesa?). São diferenças de conteúdo com implicações políticas e estéticas profundas entre companheiros de geração, que acabaram, em Brandão entre o mar e o amor, documentadas pela comparação direta entre os capítulos.

$\mathrm{Na}$ falta de um registro histórico detalhado do processo de construção da novela fora das páginas de Diretrizes, contamos apenas com o resultado final. Não temos certeza, por exemplo, se a proposta partiu de Samuel Wainer ou de Jorge Amado, mas, considerando a hipótese de ter sido o segundo, é possível que o exílio na Argentina tenha dificultado qualquer concertação mais harmônica entre os autores.

A novela costuma ser entendida como uma narrativa como forte unidade narrativa: "As células dramáticas estabelecem um intercâmbio, uma relação de osmose, num entrelaçamento que não pode fragmentar-se sem abalar todo o edifício", escreve, por exemplo, Massaud Moisés (2011, p. 114). Isso não ocorre com Brandão entre o mar e o amor. Pelo contrário, há uma ausência de unidade, o que implicaria, na leitura tradicional, uma fragilidade narrativa e uma

\footnotetext{
${ }^{8}$ Grosso modo, o realismo socialista, também chamado de zdanovismo, foi o projeto estético abraçado pelo regime soviético nos anos 1930, sob o comando de Andrej Zdanov, sobretudo a partir do $1^{\circ}$ Congresso de Escritores Soviéticos, em 1934. Esse projeto literário e artístico priorizava educação e formação das massas para o socialismo em construção e foi adotado pelos partidos comunistas ao redor do mundo, inclusive no Brasil. Há vasta polêmica sobre o tema. Para um resumo mais abrangente de sua significação, ver ENCICLOPÉDIA, 2021, verbete "Realismo socialista".
} 
dificuldade de estabelecer um pacto entre os autores e os leitores. Villares afirma, inclusive, que falta ao grupo "um real e profundo processo de criação coletiva" (2013, p. 14).

Ocorre, no entanto, que essa obra não foi inicialmente pensada como um livro, mas como um produto literário jornalístico. A relação entre os autores e o leitor, nesse caso, foi estabelecida por uma série de condicionantes próprias do jornalismo: a leitura semanal em meio a outros artigos, o noticiário da guerra, a adesão do Brasil às forças aliadas, a pressão da censura do Estado Novo, o concurso publicitário proposto pela revista. São essas condicionantes, e não as regras de leitura que normalmente aplicamos às novelas em livro, que definem a relação entre autores e leitores desse jogo literário. Assim, entendemos que uma das principais causas dessa ausência de unidade reside no fato de essa obra literária ter tido sua origem no jornal, espaço onde a fragmentação discursiva, longe de ser um problema, constitui um alicerce legitimador desses escritores dedicados à literatura do real.

\section{REFERÊNCIAS}

AMADO, Jorge. Mais que branca, mais que pálida. In: AMADO, Jorge; REGO, José Lins do; RAMOS, Graciliano; MACHADO, Aníbal; QUEIROZ, Rachel de. Brandão entre o mar e o amor. Rio de Janeiro: Record, 2000. p. 7-44.

AMADO, Jorge. O país do carnaval. Fixação do texto por Paloma Amado e Pedro Costa sob a orientação do autor. Lisboa: Dom Quixote, 2010 [1931].

AMARAL, Antônio José Azevedo. O Estado autoritário e a realidade nacional. Rio de Janeiro: José Olympio, 1938.

BARTHES, Roland. Efeito de real. In: BARTHES, Roland et al. Literatura e semiologia. Petrópolis: Vozes, 1971.

BUENO, Luís. Uma história do romance de 30. São Paulo-Campinas: Edusp; Editora Unicamp, 2006.

CANDIDO, Antonio. Fiç̧ão e confissão; Ensaios sobre Graciliano Ramos. São Paulo: Editora 34, 1999 [1992].

DIRETRIZES - 1938-1946. Coleção digitalizada. Números 58 a 109. Disponível em <http://memoria.bn.br/ DocReader/DocReader.aspx?bib=163880 >. Acesso em: 30/05/2020.

ENCICLOPÉDIA Itaú Cultural de Arte e Cultura Brasileira. São Paulo: Itaú Cultural, 2021. Disponível em: $<$ http://enciclopedia.itaucultural.org.br/pessoa7219/anibal-machado $>$. Acesso em: 28 de julho de 2021.

FERNANDES, Maria Fernanda Lombardi. Azevedo Amaral e a revista Nova Diretrizes: um projeto de modernização autoritária do Brasil. Anais do $9^{\circ}$ encontro da Associação Brasileira de Ciência Política. Brasília: ABCP, 2014. Disponível em: <https://periodicos.ufpe.br/revistas/politicahoje/article/view/234384>. Acesso em: 30/05/2020.

FERRARI, Danilo Wenseslau. Diretrizes: a primeira aventura de Samuel Wainer. Histórica - Revista eletrônica do Arquivo Público do Estado de São Paulo, São Paulo: Arquivo Público do Estado de São Paulo, n. 31, 
p. 1-59, 2008. Disponível em: <http://www.arquivoestado.sp.gov.br/site/assets/publicacao/anexo/historica31. pdf\#page $=02>$. Acesso em: 30/05/2020.

GIMENEZ, Erwin Torralbo. Graciliano Ramos, uma poética da insignificância. Revista Estudos Avançados. São Paulo: IEB-USP, v. 23, n. 67, p. 231-250, 2009.

MACHADO, Aníbal. O mar triunfante. In: AMADO, Jorge; REGO, José Lins do; RAMOS, Graciliano; MACHADO, Aníbal; QUEIROZ, Rachel de. Brandão entre o mar e o amor. Rio de Janeiro: Record, 2000. p. 87-130.

MENEZES, Carlos. "Brandão, entre o mar e o amor surgiu de uma brincadeira na casa de Aníbal Machado". O Globo, caderno "Cultura", 27/11/1981, p. 34.

MOISÉS, Massaud. A criação literária. 23. ed. São Paulo: Cultrix, 2011 [1967].

QUEIROZ, Eça de. Obras de Eça de Queiroz. V. 3. Porto: Lello \& Irmão Editores, 1958.

QUEIROZ, Rachel de. Quinta parte. In: AMADO, Jorge; REGO, José Lins do; RAMOS, Graciliano; MACHADO, Aníbal; QUEIROZ, Rachel de. Brandão entre o mar e o amor. Rio de Janeiro: Record, 2000. p. 131-157.

RAMOS, Graciliano. Angústia. Rio de Janeiro: José Olympio Editora, 1936.

RAMOS, Graciliano. Infância. Rio de Janeiro: José Olympio Editora, 1945.

RAMOS, Graciliano. Mário. In: AMADO, Jorge; REGO, José Lins do; RAMOS, Graciliano; MACHADO, Aníbal; QUEIROZ, Rachel de. Brandão entre o mar e o amor. Rio de Janeiro: Record, 2000. p. 63-86.

REGO, José Lins do. Mistério de Brandão (Glória). In: AMADO, Jorge; REGO, José Lins do; RAMOS, Graciliano; MACHADO, Aníbal; QUEIROZ, Rachel de. Brandão entre o mar e o amor. Rio de Janeiro: Record, 2000. p. 45-62.

SODRÉ, Nelson Werneck. A história da imprensa no Brasil. 4. ed. (atualizada). Rio de Janeiro: Mauad, 1999. SOUZA, Angela Leite de. Tentativa curiosa de romance a dez mãos. O Globo, 6/12/1981, p. 5.

TEIXEIRA, Marcos Vinícius. Entre a cidade alta e a fazenda de Pau d'Arco: uma leitura de Brandão entre o mar e o amor. Investigações, Recife, v. 32, n. 1, p. 155-170, 2019.

VILLARES, Lúcia. Masculinity and Disease: the Male Body in the co-authored novel Brandão entre o Mar e o Amor. Mimeo, 2013. Inédito.

WAINER, Samuel. Minha razão de viver - Memórias de um repórter. 14. ed. Rio de Janeiro: Record, s/d [1987]. 